\title{
Molal Solubility, Dissociation, Association and Solvation Parameters for Saturated Phenylalanine Solutions in Various Solvents at 298.15 K
}

\author{
Esam A. Gomaa \\ Chemistry Department, Faculty of Science, Mansoura University, Mansoura, 35516, Egypt
}

\begin{abstract}
The molal solubilities for saturated solutions of phenylalanine at $298.15 \mathrm{~K}$ in various solvents were determined. The solvents used are, water (W), ethanol (Et), dimethylsulphoxide (DMSO), acetonitrile (AN), methanol (Me), acetone (Ac), 1-4, dioxane (Di) and N, N-dimethylformamide (DMF).From the experimental data for solubilities, $\mathrm{pH}$ and densities, the different volumes, molar: electrostriction and Van der Waals and apparent molar volumes were estimated. The free energies of dissociation $\left(\Delta \mathrm{G}_{\mathrm{d}}\right)$, free energies of association $\left(\Delta \mathrm{G}_{\mathrm{A}}\right)$, difference free energies $(\Delta \Delta \mathrm{G})$ and free energies of solvation $\left(\Delta \mathrm{G}_{\mathrm{s}}\right)$ for phenylalanine saturated solutions in various solvents were also calculated. The solvation numbers were also estimated. It was concluded that the solute-solvent interaction increased by increasing the solvation free energies due mainly to the greater of the association parameters in the organic solvents.
\end{abstract}

Keywords Solubility, Association Constants, Dissociation Constants, Densities, Different Volumes, Free Energies, Solvation Number, Phenylalanine

\section{Introduction}

Knowledge of the existence of amino acids dates back over a century in many cases, as doe's knowledge of their extended in proteins. When amino acids were discovered, their identity was established by isolating and purring the individual compounds and obtaining elemental analysis. After the advent of paper chromatography, this technique was used with a variety of different solvents to identify elution characteristic and demonstrate the purity of isolated compounds. Amino acids were located by the use of a reagent that produced colour with the compound. The most common reagent used for locating amino acids is ninhydrin. Which produces a purple colour with imines, a pink or yellow color with amino acids, and various intermediate colors, with compounds containing an amino group and a sulfonid group and so on. It also reacts with small peptides such as glutathione. The techniques of paper chromatography were applied to the separation of mixtures of amino acids, such as the components of the protein after hydrolysis, and then to the separation of free amino acids in physiologic fluids and tissues.

It was extended by the use of two dimensional chromatography, in which a different solvent was used in each

\footnotetext{
* Corresponding author:

esam_1947@hotmail.com (Esam A. Gomaa)

Published online at http://journal.sapub.org/ajb

Copyright (C) 2012 Scientific \& Academic Publishing. All Rights Reserved
}

direction[1]. Later electrophoresis was employed as one of the separating techniques. After locating the amino acids by reaction with ninhydrin, the spots could be cut out, eluted with alcohol or acetone and measured spectrophotometrically[2]. In order to measure the free amino acids in biological tissues and fluids, all proteins must be removed. Various methods have been employed to accomplish this, such as ultra filtration, equilibrium dialysis, and proton precipitation. A Variety of protein precipitation has been employed for this purpose, the most common being picric acid. For extracting tissues the most common methods employ $10 \%$ trichloroacetic acid, usually by blending or homogenizing with $510 \mathrm{vol}$ of acid followed by a high speed centrifugation[2]. Plasma, cerebrospinal fluid and urine are most commonly deproteinized using 5 vol 3\% sulphosalicylic acid as protein precipitated, again followed by centrifugation. The precipitated proteins can be purified by washing with hot trichloroacetic acid to remove nucleic acids and with a Varity of organic solvents to remove lipids. The proteins can then be hydrolysed, usually with $6 \mathrm{~N} \mathrm{HCl}$ under vacuum at $120^{\circ} \mathrm{C}$ for $24 \mathrm{~h}$ or more, and their amino acid composition determined[3].

Many publications have done on the behaviour of weak acids in anhydrous solvents. Interesting work has been done by Kolthoff et al.[4,5]. Aleksandrov et al.[6,7] studied the dissociation of salicylic acid in butane-2-one. Kreshkov et al.[8] studied the dissociation of amino acids (as weak) acids) in mixtures of formic and ethylmethylketone and in mixtures of acetic acid-ethylmethylketone. 
Gomaa et al.[9] studied association, dissociation and hydrogen bonding of salicylic acid in water- $\mathrm{N}, \mathrm{N}$ - dimethylformamide mixtures from solubility measurements.

The aim of this work is to evaluate the solubility of phenylalanine in different solvents and discuss in details the solvation parameters for the solubility process. Study the effect of different solvents of the solubility and the physical behaviour accompanied is very important for the biochemical analysers. Also apply a theoretical model for evaluating different microscopic interactions of phenylalanine is necessary.

The aim of this work is to evaluate the solubilities of phenylalanine in different solvents and discuss in details the solvation parameters for the solubility processes for phenylalanine which is one of the most essential amino acids.

\section{Experimental}

The phenylalanine and solvents used, ethanol (Et), dimethylsulphoxide (DMSO), acetonitrile (AN), methanol $(\mathrm{Me})$, acetone (Ac), 1-4 dioxane (Di) and dimethylformamide (DMF) were supplied from Merck. The saturated solutions of phenylalanine were prepared by dissolving it in the solvents used. The solutions were saturated with $\mathrm{N}_{2}$ gas in closed test tubes. The tubes were placed in a shaking water bath of the type assistant for a period of four days, followed by another two days without shaking to reach the necessary equilibrium.

The solubility of phenylalanine in each solution was determined gravimetrically by taking $1 \mathrm{ml}$ of the saturated solution and subjecting it to complete evaporation using small aluminium disks heated by an infrared lamp.

The $\mathrm{pH}$ readings of the saturated solutions were measured using a pH-meter of the type Tacussel /Minis 5000. The densities were measured by using weighing bottle $1 \mathrm{ml}$ and analytical balance (4 digits) of the type Mettler Toledo DA.

\section{Results and Discussion}

Table 1. Molal solubilities (m), densities (d) and $\mathrm{pH}$ values for saturated phenylalanine solution in different solvents at $298.15 \mathrm{~K}$

\begin{tabular}{|c|c|c|c|}
\hline Solvent & $\begin{array}{c}\mathrm{m} /(\mathrm{g} \cdot \mathrm{mol} / \mathrm{kg} \\
\text { solvent) }\end{array}$ & $\mathrm{d}$ & $\mathrm{pH}$ \\
\hline $\mathrm{H}_{2} \mathrm{O}$ & 0.1535 & 1.0246 & 6.760 \\
\hline Et ( Ethanol) & $2.4470 \times 10^{-3}$ & 0.8255 & 7.352 \\
\hline DMSO (Dimethyl sulphoxide) & 0.0071 & 1.1136 & 9.496 \\
\hline AN (Acetonitrile) & $7.0530 \times 10^{-5}$ & 0.7785 & 10.816 \\
\hline $\mathrm{Me}$ (Methanol) & $2.3210 \times 10^{-2}$ & 0.8167 & 7.240 \\
\hline Di (Dioxane) & $1.08780 \times 10^{-3}$ & 1.0296 & 5.616 \\
\hline Ac (Acetone) & $1.4490 \times 10^{-3}$ & 0.8008 & 8.210 \\
\hline DMF (Dimethylformamide) & $2.6581 \times 10^{-3}$ & 0.9529 & 10.048 \\
\hline
\end{tabular}

Amino acid contents have been studied in a variety of biological samples. Of these, plasma, urine, cerebrospinal fluid, which are accessible and clinically significant, have received most attention of these samples investigated include amniotic fluid, blood cells, fees, sweat, saliva, hair, finger- nails and fingerprints. Even small amounts of protein in biological samples interfere in chromatographic analysis and have been removed.Therefore solubility measurements are very important to solve this problem[1].

The calculated molal solubilities $(\mathrm{m})$ phenylalanine saturated solution was given in Table (1) from at least three average measurements. Also the measured densities and $\mathrm{pH}$ values of the amino acid used are also listed in Table (1).

The molar volumes $\left(\mathrm{V}_{\mathrm{M}}\right)$ of phenylalanine were obtained by dividing the molar mass by the densities and their values are listed in Table (2). The packing density as reported by Kim et al.[10] and El-Khouly et. al.[11], i.e. the relation between Van der Waals volume $\left(\mathrm{V}_{\mathrm{W}}\right)$ and the molar volume $\left(\mathrm{V}_{\mathrm{M}}\right)$ of relatively large molecules (above 40 ) was found to be a constant value and equal to 0.661 .

$$
P=\frac{V_{W}}{V_{M}}=0.661 \pm 0.017
$$

The electrostriction volume $\left(\mathrm{V}_{\mathrm{e}}\right)$ which is the volume compressed by the solvent, was calculated by using equation (2) after El-Khouly[12].

$$
\mathrm{V}_{\mathrm{e}}=\mathrm{V}_{\mathrm{W}}-\mathrm{V}_{\mathrm{M}}
$$

The molar, Van der Waals and electrostriction volumes of phenylalanine in various solvents at $298.15 \mathrm{~K}$ were tabulated in Tables (2).

The different association, dissociation parameters were calculated using model explained before by us concentrating phenylalanine zwitter ion has effective hydrogen atom and that is clear from the $\mathrm{pH}$ values which are in weak organic acid range. Various analytical methods have been described in literature, only a few were developed for clinical use. For a good route analytical procedure, several factors have to be considered. Cost (both time and money), choice of simple reagent, simplicity of the procedure, and chromatographic properties of derivatives[2]. In this work simple and cheap methods for analysis can be used.

Table 2. Molar volumes $\left(\mathrm{V}_{\mathrm{M}}\right)$, Van der Waals volumes $\left(\mathrm{V}_{\mathrm{W}}\right)$, electrostriction volumes $\left(\mathrm{V}_{\mathrm{e}}\right)$ and apparent molar volumes $\left(\mathrm{V}_{\phi}\right)$ for saturated solutions of phenylalanine in different solvents at $298.15 \mathrm{~K}$ (in cm$/ \mathrm{mole})$

\begin{tabular}{|c|c|c|c|c|}
\hline Solvent & $\mathrm{V}_{\mathrm{M}}$ & $\mathrm{V}_{\mathrm{W}}$ & $-\mathrm{V}_{\mathrm{e}}$ & $\mathrm{V}_{\phi}$ \\
\hline $\mathrm{H}_{2} \mathrm{O}$ & 161.2191 & 106.5658 & 54.6530 & 161.0436 \\
\hline $\mathrm{Et}$ & 200.0993 & 132.2650 & 67.8337 & 174.6008 \\
\hline $\mathrm{DMSO}$ & 148.3373 & 98.0510 & 50.2863 & 146.2907 \\
\hline $\mathrm{AN}$ & 212.1846 & 140.2540 & 71.9300 & 171.8580 \\
\hline $\mathrm{Me}$ & 202.2670 & 133.6980 & 68.5690 & 200.2480 \\
\hline $\mathrm{Di}$ & 160.4360 & 106.0490 & 54.3880 & 158.0711 \\
\hline $\mathrm{Ac}$ & 206.2780 & 136.3500 & 68.9280 & 188.9220 \\
\hline $\mathrm{DMF}$ & 173.3550 & 114.5870 & 58.7680 & 169.7592 \\
\hline
\end{tabular}

The apparent molar volumes $\mathrm{V}_{\phi}[13-15]$ were calculated using equation (3)[16]

$$
\mathrm{V}_{\varphi}=\mathrm{M} / \mathrm{d}_{\mathrm{o}}-\left(\mathrm{d}-\mathrm{d}_{\mathrm{o}} / \mathrm{dd}_{\mathrm{o}}\right) 1000 / \mathrm{m}
$$

Where $\mathrm{M}$ is the molar mass of benzoic acid, $\mathrm{m}$ is the concentration; $d$ and $d_{o}$ are the densities of saturated solution and pure solvents, respectively.

The values of $\mathrm{V}_{\phi}$ for phenylalanine in various solvents at $298.15 \mathrm{~K}$ are presented in Table (2).

The activity coefficient was calculated by using the relation $\log \gamma_{ \pm}=-0.5062 \sqrt{m}[17,18]$. 
$\mathrm{K}_{\text {ass }}$ values were calculated[14] from the ratios of association constant to dissociation constant (i.e., $\mathrm{K}_{1} / \mathrm{K}_{2}$ ) for the dimmers of phenylalanine which form a complex ion $\left(\left(H A_{2}^{-}\right)\right.$ and hydrogen ion $\left(\mathrm{H}^{+}\right)$, and the values of $\mathrm{K}^{\prime}$ (where $\mathrm{K}^{\prime}$ is the dissociation constant of the associated acid complex, $\mathrm{H}_{2} \mathrm{~A}_{2}$ ) are given by the following equations

$$
\begin{gathered}
\mathrm{K}^{\prime}=\mathrm{a}^{2} \mathrm{H}^{+} / \mathrm{m}^{2} \\
\mathrm{PaH}^{+}=\frac{1}{2} \log \frac{K_{1}}{K_{2}}-\log m=\mathrm{pH}-\log \gamma_{ \pm} \\
\frac{K_{1}}{K_{2}}=K^{\prime} K_{\text {ass }}
\end{gathered}
$$

Where $a$ is the activity. The values obtained $\mathrm{K}_{1} / \mathrm{K}_{2}, \mathrm{~K}^{\prime}$ and $\mathrm{K}_{\text {ass }}$ are reported in Table (3). The maximum value of $\mathrm{K}_{\text {ass }}$ was found to be by using DMF where water is the least association parameters.

The free energies of dissociation $\left(\Delta \mathrm{G}_{\mathrm{d}}\right)$, free energies of association $\left(\Delta \mathrm{G}_{\mathrm{A}}\right)$, difference free energies $(\Delta \Delta \mathrm{G})$ and free energies of solvation $\left(\Delta \mathrm{G}_{\mathrm{s}}\right)$ for phenylalanine saturated solutions in various solvents were calculated by using the following equations and tabulated in Table (4).

$$
\begin{gathered}
\Delta \mathrm{G}_{\mathrm{d}}=-\mathrm{RT} \ln \mathrm{K}^{\prime} \\
\Delta \mathrm{G}_{\text {ass }}=-\mathrm{RT} \ln \mathrm{K}_{\text {ass }} \\
\Delta \Delta \mathrm{G}=\Delta \mathrm{G}_{\text {ass }}-\Delta \mathrm{G}_{\mathrm{d}} \\
\Delta \mathrm{G}_{\mathrm{s}}=-\mathrm{RT} \mathrm{pK} \text { sp } \\
\mathrm{pK}_{\mathrm{sp}}=-2 \log \mathrm{m}-2 \log \gamma_{ \pm}
\end{gathered}
$$

The solvation volumes for phenylalanine were evaluated from the difference between Van der Waals of phenylalanine in absence and given before in various solvents. The Van der Waals volume of phenylalanine was calculated from Bondi method[19] and found to be $222.648 \mathrm{~cm}^{3} /$ mole. Subtracting this value from $V_{w}$ in solvents and divide the results by the molar volumes of the solvents taken from ref.[18], $\mathrm{n}$ (the solvation number) was obtained and given in Table (5).

It was concluded that the solute-solvent interaction increased by increasing $\Delta \Delta \mathrm{G}$ and $\Delta \mathrm{G}_{\mathrm{s}}$ due mainly to the greatest of the association parameters in the corresponding solvents.

Also it was observed that the association, dissociation and microscopic interactions between solute and solvent is important for any solvent individually, whether it is polar, aprotic or amphiprotic.Increasing of the solvation numbers favour more solute- solvent interactions between phenylalanine and solvents. Also small solvation numbers favour more solute solute interaction or ion pair formation resulting in the decrease of the solute - solvent interactions in the solvent under discussion. Big positive values for $\Delta \Delta \mathrm{G}$ and big negative. This work gives a lot of data which help any analyst to use suitable solvent for phenylalanine in chromatographic analysis.

Table 3. Log activity coefficients $\left(\log \gamma_{ \pm}\right)$, dissociation constants $(\mathrm{K})$ and association constants for phenylalanine saturated solutions in different solvents at $298.15 \mathrm{~K}$

\begin{tabular}{|c|c|c|c|c|c|}
\hline Solvent & $\log \gamma_{ \pm}$ & $\mathrm{Pa}_{H^{+}}$ & $\mathrm{K}$ & $\frac{K_{1}}{K_{2}}$ & $\mathrm{~K}_{\text {ass }}$ \\
\hline $\mathrm{H}_{2} \mathrm{O}$ & -0.1980 & 6.9586 & $2.0610 \times 10^{3}$ & $7.8521 \times 10^{12}$ & $3.8091 \times 10^{9}$ \\
\hline $\mathrm{Et}$ & -0.0282 & 7.3802 & $9.1000 \times 10^{6}$ & $3.4101 \times 10^{8}$ & 37.3622 \\
\hline $\mathrm{DMSO}$ & -0.0041 & 9.5001 & $1.7112 \times 10^{5}$ & $5.0800 \times 10^{14}$ & $2.9900 \times 10^{7}$ \\
\hline $\mathrm{AN}$ & $-4.8100 \times 10^{-4}$ & 10.8160 & $2.3501 \times 10^{10}$ & $2.1321 \times 10^{13}$ & 907.2601 \\
\hline $\mathrm{Me}$ & -0.0860 & 5.6320 & $1.3002 \times 10^{3}$ & $3.6001 \times 10^{-4}$ & $2.7801 \times 10^{-7}$ \\
\hline $\mathrm{Di}$ & -0.0164 & 7.3260 & $2.6002 \times 10^{7}$ & $2.1010 \times 10^{5}$ & $8.0711 \times 10^{-3}$ \\
\hline $\mathrm{Ac}$ & -0.0217 & 7.3737 & $2.5801 \times 10^{6}$ & $1.1702 \times 10^{9}$ & 453.4880 \\
\hline $\mathrm{DMF}$ & -0.0268 & 10.0748 & $14.3001 \times 10^{5}$ & $9.9300 \times 10^{14}$ & $6.9100 \times 10^{7}$ \\
\hline
\end{tabular}

Table 4. Free energies of dissociation $\left(\Delta \mathrm{G}_{\mathrm{d}}\right)$, free energies of association $\left(\Delta \mathrm{G}_{\mathrm{A}}\right)$, difference free energies $(\Delta \Delta \mathrm{G})$ and free energies of solvation $\left(\Delta \mathrm{G}_{\mathrm{s}}\right)$ for phenylalanine saturated solutions in different solvents at $298.15 \mathrm{~K}$ (in kJoule/mole)

\begin{tabular}{|c|c|c|c|c|}
\hline Solvent & $\Delta \mathrm{G}_{\mathrm{d}}$ & $\Delta \mathrm{G}_{\mathrm{A}}$ & $\Delta \Delta \mathrm{G}$ & $\Delta \mathrm{G}_{\mathrm{s}}$ \\
\hline $\mathrm{H}_{2} \mathrm{O}$ & -18.919 & -54.694 & -35.775 & -10.163 \\
\hline $\mathrm{Et}$ & -39.727 & -9.000 & -12.817 & -26.507 \\
\hline $\mathrm{DMSO}$ & -29.859 & -42.676 & -5.56464 & -21.312 \\
\hline $\mathrm{AN}$ & -59.205 & -16.884 & 42.321 & -58.740 \\
\hline $\mathrm{Me}$ & -17.776 & 37.426 & 55.202 & -17.279 \\
\hline $\mathrm{Di}$ & -42.330 & 11.949 & 54.279 & -29.927 \\
\hline $\mathrm{Ac}$ & -36.602 & -15.165 & 21.437 & -28.931 \\
\hline $\mathrm{DMF}$ & -35.139 & -44.749 & -9.610 & -26.134 \\
\hline
\end{tabular}

Table 5. Molar volumes of solvents $\left(V_{s}\right)$, difference in different Van der Waals volumes $\left(\Delta \mathrm{V}_{\mathrm{w}}\right)$ and solvation numbers $\left(\mathrm{n}_{\mathrm{s}}\right)$ for phenylalanine a saturated solutions in different solvents at $298.15 \mathrm{~K}$

\begin{tabular}{|c|c|c|c|}
\hline Solvent & $\mathrm{V}_{\mathrm{s}}$ & $\Delta \mathrm{V}_{\mathrm{w}}$ & $\mathrm{n}_{\mathrm{s}}$ \\
\hline $\mathrm{H}_{2} \mathrm{O}$ & 18.0724 & 116.083 & 6.423 \\
\hline $\mathrm{Et}$ & 58.6804 & 90.383 & 1.540 \\
\hline $\mathrm{DMSO}$ & 71.2995 & 124.597 & 1.747 \\
\hline $\mathrm{AN}$ & 52.8450 & 82.394 & 1.559 \\
\hline $\mathrm{MeOH}$ & 40.7322 & 88.980 & 2.184 \\
\hline $\mathrm{Di}$ & 86.3552 & 116.599 & 1.350 \\
\hline $\mathrm{Ac}$ & 175.411 & 86.298 & 0.491 \\
\hline $\mathrm{DMF}$ & 77.4118 & 108.061 & 1.396 \\
\hline
\end{tabular}




\section{REFERENCES}

[1] Volker, F.Wedish,"Amino acid biosysthesis- pathways, regulation and metabolic enegineering", Springer - Verlag, Berlin, Heidelberg (2007).

[2] Alan A.Bculton, Glen B. Baker and James d. Wood, "Neuromethods 3, amino acid.” The Humana Press Ins, Clifton, NJ O7015 (1985).

[3] Gamerith, G., J.Chromatogr. 256, 326 (1983).

[4] Kolthoff, I.M. and Chantooni, M.K., J. Am. Chem. Soc., 87, 4428 (1965).

[5] Kolthoff, I.M., Chantooni, M.K. and Bhownik, S., J. Am. Chem. Soc., 90, 123 (1968).

[6] Aleksandrov, V.V., Zudochkina, A.I., and Sandovinchaya, L.P., Zh. Fiz. Khim., 52, 1295 (1978).

[7] Alekandrov, V.V., and Burakhovich, Fizicheskaya Khimiya Rastrorov (Physical Chemistry in Solutions), Nauka, Moscow, 1972, p. 154.

[8] Kreshkov, A.P., Tanganor, B.B., Yarovenko, A.N. and Batoreva, T. Kh., Zh. Fiz. Khim., 54, 105 (1980).
[9] Gomaa, E.A., Mousa, M.A. and El-Khouly, A.A., Thermochimica Acta, 89, 133-139 (1985).

[10] Kim, J.T., Cecal, A., Born, H.J. and Gomaa, E.A., Z. Physikalische Chemic, Neue Folge, 110, 209-227 (1978).

[11] El-Khouly, A.A., Gomaa, E.A. and Abou-El-Leef, S., Bull. of Electrochemistry, 19, 153-164 (2003).

[12] El-Khouly, A.A., Gomaa, E.A., Abou El-Leef, S., Bull. Of electrochemistry, 19, 193-202 (2003).

[13] Oswal, S.L., Desai, J.S., Ijardar, S.P. and Jain, D.M., journal of Mol. Liquids, 144, 108-114 (2009).

[14] Dorota Bobicz, Waclaw Grzybkowski and Andrzej Lwandowski, J. of Mol. Liquids, 105, 93-104 (2003).

[15] Marcus, Y. "The properties of solvents", Wiley, London, 1998.

[16] Moelwyn - Hughes, E.A., “ Physikalische Chemie ”, George Thieme Verlag, Stuttgart, 1970, p. 489.

[17] Gomaa, E.A., Mousa, M.A. and El-Khouly, Thermochim. Acta, 89, 133-139 (1985).

[18] Gomaa, Esam, A., Thermochim. Acta, 120, 183-190 (1987).

[19] Bondi, A., J. Phys. Chem., 68 (1964) 441. 